\title{
Efficacy of Early Versus Delayed Laparoscopic Cholecystectomy in Federal Government Services Hospital Islamabad
}

\author{
Amjad Ali Bhurt, Shahida Khatoon, Ahmed Ali Danish, Inayatullah Baig, Zameer Hussain Laghari
}

\begin{abstract}
Background: Acute cholecystitis is a commonest surgical issue and was mostly treated via conservative management followed by the delayed laparoscopic cholecystectomy after interval of the 6 to 8 weeks. However, by the increasing experience in the laparoscopies, surgeons started to attempt early laparoscopic cholecystectomy for acute cholecystitis. Objective: To compare the efficacy of early and delayed laparoscopic cholecystectomy in the acute phase in terms of the conversion to open cholecystectomy. Study Design: Randomized Clinical Trial. Settings: General Surgery Department of Federal Govt. Services Polyclinic Hospital, Islamabad-Pakistan. Duration: Two years from June 2014 to May 2016. Methodology: Patients with established acute cholecystitis diagnosis with age 20 to 50 years and either of gender were included. In early laparoscopic cholecystectomy; removal of gall bladder was done laparoscopically within 72 hours of onset of inflammation and in delayed procedure after 6 weeks of conservative administration. Outcome was assessed via conversion to open cholecystectomy. All the data was recorded in the self-made proforma. Results: Total 196 patients were compared for efficacy of early and delayed laparoscopic cholecystectomy. 41 to 50 years was the most common age group among both groups. Conversion to open cholecystectomy was $5.1 \%$ in early group and $6.1 \%$ was in delayed group ( $p-0.711)$. Efficacy was statistically insignificant according to age and gender $p$-values were quite insignificant. Conclusion: Early laparoscopic cholecystectomy showed good efficacy with lower conversion rate to open cholecystectomy and additional advantages of safety form extra uses of antibiotics and painkillers of conservative treatment duration.
\end{abstract}

Keywords: Early, Delayed, Laparoscopic cholecystectomy.

Corresponding Author

Submitted for Publication: 08-09-2019

Accepted for Publication: 16-11-2019

DR. AMJAD ALI BHURT, Consultant General Surgeon LUH, Ex. TRMO Federal Govt. Services Polyclinic Hospital, Islamabad-Pakistan

Contact / Email: +92 311-0980352, amjadalibhurt@gmail.com

Citation: Bhurt AA, Khatoon S, Danish AA, Baig I, Laghari ZH. Efficacy of Early Versus Delayed Laparoscopic Cholecystectomy in Federal

Government Services Hospital Islamabad. APMC 2020;14(1):20-3.

\section{INTRODUCTION}

Acute cholecystitis as a life-threatening condition affects more than five million Egyptians annually and results in high economic liability worldwide. Gallstones contributes quite enough to the acute cholecystitis. ${ }^{1}$ Laparoscopic cholecystectomy has become the recommended treatment for patients experiencing acute cholecystitis, only if it is contraindicated for medical or safety purposes. ${ }^{2}$ Cholecystectomy has been among the safest and widely recognized methods of treatment for the diseases of gall bladder . ${ }^{2}$ Acute cholecystitis has always been a major concern in gallstones. Laparoscopic cholecystectomy in acute cholecystitis has not yet become standard, as the surgical method of treatment and timing in cases of acute cholecystitis yet remains a debatable point for the general surgeons.

Surgery timing for acute cholecystitis remained problematic. Numerous studies revealed favourable results with low conversion levels if subjects are exposed to surgery during the 96 hours of admission afterwards the surgeons decided to perform interval cholecystectomy during the period of 6-8 weeks. ${ }^{3}$ Around $80 \%$ cholecystectomies are carried out laparoscopically. Traditionally, acute cholecystitis is treated conservatively followed by delayed cholecystectomy procedure following 6-8 weeks of acute attack. Laparoscopic cholecystectomy is presently the first option for the treatment of this condition, following an initial period under which it was deemed contraindicated to acute cholecystectomy. ${ }^{4}$ However, early urgent cholecystectomy was often difficult to implement due to logistical reasons related to patient comorbidities and emergent accessibility of an operating room and equipment. In the early times of laparoscopic cholecystectomy, acute cholecystitis remained a contraindication of laparoscopic cholecystectomy and several surgeons assumed it as a matter of training and skill so far. ${ }^{5}$ Several studies have reported the ideal timing of laparoscopic cholecystectomy in cases with acute cholecystitis. ${ }^{6}$ One study adopted the early laparoscopic cholecystectomy as the preferred treatment to manage acute cholecystitis because of shorter hospitalities length and no rise in morbidity in comparison to delayed cholecystectomy. ${ }^{7}$ On other hand no significant variances were mentioned in patient age, sex, postoperative stay, conversions and post-operative complications among both of the groups. ${ }^{6}$ Laparoscopic cholecystectomy in case of acute cholecystitis hasn't yet been adopted as a routine because the approach to and the timing of surgical administration in acute cholecystitis patients yet remains controversial. ${ }^{8}$ Sometimes laparoscopic cholecystectomy is converted to open procedure due to different complications. ${ }^{9}$ This study has been conducted to compare the efficacy of early and delayed laparoscopic cholecystectomies in the acute phase with regard to frequency of conversion to open cholecystectomy.

\section{METHODOLOGY}

Study Design: This was a Randomized Clinical Trial. 
Settings: Department of Surgery, Federal Polyclinic Hospital and Post Graduate Medical College, Islamabad Pakistan.

Duration: Two years from June 2014 to May 2016.

Sample Technique: Non probability consecutive sampling.

Sample Size: 196 (98 patients in each group) by using WHO sample size calculator with level of significance $5 \%$ and Power of study $80 \%$.

Inclusion Criteria: All the patients with established acute cholecystitis diagnosis with age 20 to 50 years and either of gender were included.

Exclusion Criteria: Patients with decompensated cirrhosis of liver, acute cholangitis, pancreatitis or gall bladder malignancy and patients having stones in common bile duct on ultrasonography or having obstructive jaundice were excluded. Methods: All patients were randomly allocated to either group i.e. Early or Delayed Laparoscopic Cholecystectomy Groups A and $B$ respectively based on random number table. All subjects were operated under general anaesthesia by the same laparoscopic team of surgeon.

All patients had received a single dose of antibiotic prophylactic IV one hour prior to the induction of anaesthesia. Acute Cholecystitis was defined according to characteristics of pain right hypochondrium, continuous in character lasting more than $6 \mathrm{hrs}$, confirmed by raised TLC (> 10000) and positive ultrasonographic findings (oedematous gall bladder, fluid around gall bladder. Early laparoscopic cholecystectomy is removal of gall bladder laparoscopically within 72 hours of initiation of inflammation. Delayed laparoscopic cholecystectomy was done after 6 weeks (i.e., 42 days) of conservative management of acute Cholecystitis. Outcome was assessed in terms of the conversion to open cholecystectomy, which was calculated in terms of rate of conversion in both groups, every case which was started as laparoscopic procedure and then converted to open cholecystectomy irrespective of cause of conversion. Efficacy was recorded in terms of no conversion to open cholecystectomy. Conversion to open cholecystectomy was recorded and all patients are aggressively mobilized 10 ambulate on the surgical procedure day or the post-operative day 1 . All the data was recorded in the self-made proforma.

Statistical Analysis: Data was recorded and analysed in SPSS version 20.0. Qualitative variables were calculated as frequencies and percentages. Mean and Standard deviation were calculated for quantitative variables like age. Chi-square test was used and a $\mathrm{P}<0.05$ was taken as significant.

\section{RESULTS}

Mean age of group A was $28.53 \pm 6.92$ years, minimum 22 years and maximum 42 years. Mean age of group B was $29.42+8.43$ years minimum 25 years and maximum 45 years. Most common age was 41 to 50 years among both groups; findings were statistically insignificant ( $\mathrm{p}-0.061)$.

$50(51.0 \%)$ were males and $48(49.0 \%)$ females in group A while $38(38.8 \%)$ males and $60(61.2 \%)$ were females in group $B$, females were statistically significant in group $B(p-0.018)$. Table 1
Table 1: Patient's distribution according to age and gender $\mathrm{n}=196$

\begin{tabular}{|c|c|c|c|c|}
\hline \multirow{2}{*}{\multicolumn{2}{|c|}{ Variables }} & \multicolumn{2}{|c|}{ Study groups } & \multirow{2}{*}{$\begin{array}{c}\mathrm{p}- \\
\text { value }\end{array}$} \\
\hline & & \multirow{2}{*}{$\begin{array}{c}\text { Group A } \\
15(15.3 \%)\end{array}$} & \multirow{2}{*}{$\begin{array}{c}\text { Group B } \\
09(9.2 \%)\end{array}$} & \\
\hline \multirow{4}{*}{$\begin{array}{c}\text { Age } \\
\text { groups }\end{array}$} & 20 to 30 years & & & \multirow{4}{*}{0.061} \\
\hline & 31 to 40 years & $30(30.6 \%)$ & $20(20.4 \%)$ & \\
\hline & 41 to 50 years & $53(54.1 \%)$ & $69(70.4 \%)$ & \\
\hline & Total & $98(100.0 \%)$ & $98(100.0 \%)$ & \\
\hline \multirow{3}{*}{ Gender } & Male & $50(51.0 \%)$ & $38(38.8 \%)$ & \multirow{3}{*}{0.018} \\
\hline & Female & $48(49.0 \%)$ & $60(61.2 \%)$ & \\
\hline & Total & $98(100.0 \%)$ & $98(100.0 \%)$ & \\
\hline
\end{tabular}

Group A= Early laparoscopic cholecystectomy,

Group B= Delayed laparoscopic cholecystectomy

Efficacy of early laparoscopic cholecystectomy was higher as conversion to open cholecystectomy was done in only 5 cases, which was significantly lower in contrast to Delayed laparoscopic cholecystectomy ( $p-0.071)$. Table 2

Table 2: Comparison of conversion to open cholecystectomy in both groups $n=196$

\begin{tabular}{|c|c|c|c|}
\hline \multirow{2}{*}{$\begin{array}{c}\text { Conversion to open } \\
\text { cholecystectomy }\end{array}$} & \multicolumn{2}{|c|}{ Study groups } & \multirow{2}{*}{$\begin{array}{c}\text { p- } \\
\text { value }\end{array}$} \\
\hline Yes & Group A & Group B & \\
\hline No & $5(5.1 \%)$ & $06(6.1 \%)$ & \\
& $93(94.9 \%)$ & $93(93.9 \%)$ & \multirow{2}{*}{0.071} \\
\hline Total & $98(100.0 \%)$ & $98(100.0 \%)$ & \\
\hline
\end{tabular}

Group A= Early laparoscopic cholecystectomy, Group B= Delayed laparoscopic cholecystectomy

Efficacy was statically insignificant according to age ( $p-0.718)$, 2 patients were of age group 31-40 years and 3 patients of age group 41-50 years in group A. Similarly, 7 patients of group 3140 years and 3 patients of age group 41-50 years in group B. According to the gender out of five cases of group A 3 were males and 2 were female, and out of 14 cases of group $B, 8$ were males and 6 were females ( $p-0.718)$. (Table 3 )

Table 3: Conversion to open cholecystectomy according to age and gender in both groups $n=196$

\begin{tabular}{|c|c|c|c|c|}
\hline \multicolumn{2}{|c|}{ Variable } & \multicolumn{2}{c|}{ Study groups } & \multirow{2}{*}{ p-value } \\
\cline { 3 - 4 } & Group A & Group B & \\
\hline \multirow{3}{*}{ Gender } & Male & 03 & 03 & \multirow{3}{*}{0.418} \\
\cline { 2 - 4 } & Female & 02 & 03 & \\
\cline { 2 - 4 } & Total & 05 & 14 & \\
\hline \multirow{4}{*}{ Age groups } & $20-30$ years & 00 & 01 & \multirow{4}{*}{0.718} \\
\cline { 2 - 4 } & $31-40$ years & 02 & 02 & \\
\cline { 2 - 4 } & $41-50$ years & 03 & 03 & \\
\cline { 2 - 4 } & Total & 05 & 14 & \\
\cline { 2 - 4 } & & & \\
\end{tabular}

Group A= Early laparoscopic cholecystectomy, Group B= Delayed laparoscopic cholecystectomy 


\section{DISCUSSION}

Elective laparoscopic cholecystectomy is now the benchmark for symptomatic gallstone treatment. ${ }^{10}$ Acute cholecystitis, however, was a contraindication of laparoscopic cholecystectomy in early times, and acute cholecystitis cases were treated conservatively and released from hospital for re-admission to have elective surgical procedure performed for final care.10,11 Then, meta-analyses and randomized controlled trials showed the advantages of early surgical procedure (shorter period after presentation i.e., twenty four to seventy two hours) than the delayed cholecystectomy procedure in regard to shorter period of Hospitalization and low cost including insignificant morbidity and mortality. ${ }^{10-12}$

Present study was conducted to contrast the efficacy with regard to conversion rate and in this study efficacy of early laparoscopic cholecystectomy was higher as conversion to procedure of open cholecystectomy was in only 5 cases, which was lower than delayed laparoscopic cholecystectomy ( $p$ 0.071 ), including advantages of short disease duration and lower cost. On other hand Özkardeş $A B$ et a/10 reported that intraoperative and postoperative complications higher in early laparoscopic cholecystectomy as compared to delayed, even though early laparoscopic cholecystectomy needs be preferred due to low cost and shorter hospital stay for the acute cholecystitis treatment. Lyu $\mathrm{Y}$ et al, ${ }^{13}$ reported early laparoscopic cholecystectomy as effective and safe in contrast to delayed laparoscopic cholecystectomy for acute cholecystitis treatment within seven days with less Hospital stay. Whereas Agrawal $\mathrm{R}$ et al ${ }^{14}$ observed similar findings.

In this study conversion rate was $5.1 \%$ among cases of early laparoscopic cholecystectomy and $9.25 \%$ among cases of delayed laparoscopic cholecystectomy, but statistically insignificant. Similarly, Özkardeş AB et a/ ${ }^{10}$ reported that there was insignificant difference with regard to operation time and conversion rate between both groups. In a randomized, controlled trial early laparoscopic cholecystectomy (less than 24 hours) in 75 patients showed decrease in morbidity in the course of interval for elective laparoscopic cholecystectomy, the rate of conversion to the procedure of open cholecystectomy, hospital stay, and operating time. ${ }^{15}$ While inconsistently Agrawal $\mathrm{R}$ et a/ ${ }^{14}$ reported that conversion rate of early laparoscopic cholecystectomy group was $16 \%$ and in cases of delayed laparoscopic cholecystectomy group was $8 \%$. Minutolo et al ${ }^{16}$ in their study reported conversion rate in early group to be $34.3 \%$ and in their delayed group to be $20.3 \%$, but the difference was statistically non-significant $(p=0.223)$. Jamil $M$ et a/ ${ }^{17}$ reported that Conversion rate to open cholecystectomy was $7.55 \%$ in early and $10 \%$ in delayed group. On other hand Akhtar $\mathrm{NN}$ et al ${ }^{19}$ also found conversion rates of $13.33 \%$ in early laparoscopic cholecystectomy and $9.33 \%$ in delayed laparoscopic cholecystectomy.

In this study mean age of group A was $28.53+6.92$ years, and group b was $29.42 \pm 8.43$ years. On other Imbisat $M Z$ et al/18 also found mean age in early group with as $42.28 \pm 12.98$ years and in the delayed group as $43.08 \pm 13.62$ years. Jamil $M$ et a/17 reported that mean age was $40.21 \pm 3.33$ years early laparoscopic cholecystectomy and $42.87 \pm 4.54$ years in delayed laparoscopic cholecystectomy. In this study $50(51.0 \%)$ were males and $48(49.0 \%$ ) females in group A while $38(38.8 \%)$ males and $60(61.2 \%)$ were females in group $B$, females were statistically significant in group B ( $p-0.018)$. Similarly, females were $44 \%$ in early laparoscopic cholecystectomy and $60 \%$ cases of delayed laparoscopic cholecystectomy, while $56 \%$ were males in early laparoscopic cholecystectomy and $40 \%$ in delayed laparoscopic cholecystectomy.

\section{CONCLUSION}

Early laparoscopic cholecystectomy showed good efficacy in terms of insignificant conversion rate to open cholecystectomy. Though early laparoscopic cholecystectomy should be preferred for additional advantages as; safety forms extra uses of antibiotics and painkillers of conservative treatment duration.

\section{LIMITATIONS}

Laparoscopic cholecystectomy is very frequently done all over the world. This was a single centre and small sample size.

\section{SUGGESTIONS / RECOMMENDATIONS}

Further multi centre studies are required on this subject.

\section{CONFLICT OF INTEREST / DISCLOSURE}

No conflict of interest.

\section{ACKNOWLEDGEMENTS}

Authors have acknowledged their supervisor and seniors, for their guidelines and support.

\section{REFERENCES}

1. Salem YK, AlShamy AM, Abd El Moaty KF. Current Perspective of Laparoscopic Cholecystectomy for Acute Cholecystitis. The Egyptian Journal of Hospital Medicine. 2018;72(7):4885-93.

2. Chhajed R, Dumbre R, Fernandes A, Phalgune D. Early versus delayed laparoscopic cholecystectomy for acute cholecystitis: a comparative study. In Sur J. 2018;5(10):3381-5.

3. Taha AM, Mohamed Yousef A, Gaber A. Early Versus Delayed Laparoscopic Cholecystectomy for Uncomplicated Acute Cholecystitis. J Surg. 2016;17:4(3-1):29-33.

4. Teixeira JP, Ribeiro C, Moreira LM, de Sousa F, Pinho A, Graça L, Maia C. Laparoscopic Cholecystectomy in Acute Cholecystitis in Septuagenarians. J Transl Med Res. 2016;21(4):274.

5. Ohta M, Iwashita Y, Yada K, Ogawa T, Kai S, Ishio T, Shibata K, Matsumoto T, Bandoh T, Kitano S. Operative timing of laparoscopic cholecystectomy for acute cholecystitis in a Japanese institute. JSLS. 2012;16(1):65.

6. Mahapatra B, Deolekar SR, Subudhi S. Early laparoscopic cholecystectomy in acute cholecystitis: Preferable option. Inter J Surg. 2019;3(4):345-8.

7. Borzellino G, Khuri S, Pisano M, Mansour S, Allievi N, Ansaloni L, Kluger Y. Timing of early laparoscopic cholecystectomy for acute calculous cholecystitis revised: Protocol of a systematic review and meta-analysis of results. World J Emerg Surg. 2020;15(1):1. 
8. Arafa AS, Khairy MM, Amin MF. Emergency versus delayed laparoscopic cholecystectomy for acute cholecystitis. Egypt J Surg. 2019;38:171-9

9. Zaidi AH, Halim A, Azami R, Rana SH, Naqvi S, Shan A. Complications in laparoscopic cholecystectomy. APMC 2015;9(2):57-65.

10. Özkardeş $A B$, Tokaç M, Dumlu EG, Bozkurt B, Çiftçi $A B$, Yetişir F, Kilıç M. Early versus delayed laparoscopic cholecystectomy for acute cholecystitis: a prospective, randomized study. International surgery. 2014;99(1):56-61.

11. Gurusamy K, Samraj K, Gluud C, Wilson E, Davidson BR. Metaanalysis of randomized controlled trials on the safety and effectiveness of early versus delayed laparoscopic cholecystectomy for acute cholecystitis. $\mathrm{Br} J$ Surg. 2010;97(2):141-50

12. Chang TC, Lin MT, Wu MH, Wang MY, Lee PH. Evaluation of early versus delayed laparoscopic cholecystectomy in the treatment of acute cholecystitis. Hepatogastroenterology. 2009;56(89):26-8.

13. Lyu $Y$, Cheng $Y$, Wang B, Zhao S, Chen L. Early versus delayed laparoscopic cholecystectomy for acute cholecystitis: an up-to- date meta-analysis of randomized controlled trials. Surgical endoscopy. 2018;32(12):4728-41.

14. Agrawal R, Sood KC, Agarwal B. Evaluation of early versus delayed laparoscopic cholecystectomy in acute cholecystitis. Surgery research and practice. 2015;2015.

15. Gurusamy KS, Samraj K, Fusai G, Davidson BR. Early versus delayed laparoscopic cholecystectomy for biliary colic. Cochrane Database Syst Rev. 2008;(4):CD007196

16. Minutolo V, Licciardello A, Arena M, Nicosia A, Di Stefano B, Cali $G$, et al. Laparoscopic cholecystectomy in the treatment of acute cholecystitis: comparison of outcomes and costs between early and delayed cholecystectomy. Eur Rev Med Pharmacol Sci. 2014;18(2):40-6.

17. Jamil M, Niaz K, Ali A, Saeed S. Laparoscopic cholecystectomy for acute cholecystitis: early versus delayed. Rawal Med J. 2014;39(2):199-202.

18. Imbisat MZ, Rizvi SAA, Ali I. An evaluation of early and delayed laparoscopic cholecystectomy for acute cholecystitis. Int Surg J 2019;6:1-5.

19. Akhtar NN, Fawad A, Allam KM. Early Versus Delayed Laparoscopic Cholecystectomy in Acute Cholecystits. PJMS. 2016;10(3):1039-43.

\section{AUTHORSHIP AND CONTRIBUTION DECLARATION}

\begin{tabular}{|c|c|c|}
\hline AUTHORS & Contribution to The Paper & Signatures \\
\hline $\begin{array}{l}\text { Dr. Amjad Ali Bhurt } \\
\text { Consultant General Surgeon LUH } \\
\text { Ex. TRMO Federal Govt. Services Polyclinic Hospital } \\
\text { Islamabad }\end{array}$ & Conduct the study as principle author & \\
\hline $\begin{array}{l}\text { Dr. Shahida Khatoon } \\
\text { Associate Professor of General Surgery, Liaquat } \\
\text { University of Medical and Health Sciences, } \\
\text { Hyderabad-Pakistan }\end{array}$ & Contribution in data collection and manuscript writing & \\
\hline $\begin{array}{l}\text { Dr. Ahmed Ali Danish } \\
\text { Medical Officer, General Surgery Liaquat University } \\
\text { of Medical and Health Sciences, Hyderabad- } \\
\text { Pakistan }\end{array}$ & Contribution in data analysis and manuscript writing & \\
\hline $\begin{array}{l}\text { Dr. Inayatullah Baig } \\
\text { Consultant General Surgeon \& Head of Department } \\
\text { of Surgery at Federal Govt. services polyclinic } \\
\text { Hospital Islamabad Pakistan }\end{array}$ & Review the manuscript and supervision & \\
\hline $\begin{array}{l}\text { Dr. Zameer Hussain Laghari } \\
\text { Associate Professor, General Surgery Department of } \\
\text { Liaquat University of Medical and Health Sciences, } \\
\text { Jamshoro Pakistan }\end{array}$ & Contribution in data analysis & \\
\hline
\end{tabular}

